\title{
A educação e o destino social em análise
}

\author{
Education and social destiny under analysis
}

BOURDIEU, Pierre; PASSERON, Jean-Claude. Os herdeiros: os estudantes e a cultura. Tradução de lone Ribeiro Valle e Nilton Valle. Florianópolis: Editora da UFSC, 2014.

Cristiano Mezzaroba

Universidade Federal de Sergipe

Desvelar, indagar, refletir - termos sempre comuns às obras de Pierre Bourdieu que, no livro Os herdeiros - os estudantes e a cultura, com autoria compartilhada de Jean-Claude Passeron, publicada originalmente em francês em 1964 e pela primeira vez traduzida para o português em 2014 por lone Ribeiro Valle e Nilton Valle, são novamente colocados à prova (empiricamente) em relação àquele que poderia ser eleito como o "objeto" principal da obra acadêmica e intelectual de Bourdieu: a educação escolar em seu caráter de denúncia quanto ao destino social que essa instituição produz àqueles que dela fazem parte.

Publicado como livro, que se apresenta como um verdadeiro relatório de pesquisa, quantitativamente, em relação à sua totalidade de páginas, quase metade delas é dedicada aos dados empíricos organizados em tabelas e gráficos com sínteses sucintas, em forma de Apêndice, com os dados estatísticos dos estudantes franceses entre 1960 e 1963. Anterior ao apêndice, logo após a lista desses gráficos e tabelas que geram a discussão do livro, há a apresentação da obra, escrita por lone Ribeiro Valle, que questiona "Por que ler Os herdeiros meio século depois?", e na sequência, uma "Advertência", momento em que os autores justificam a origem dos dados analisados na obra e explicam o porquê da escolha dos estudantes de letras terem tido lugar particular nas análises realizadas. Seguem-se, a partir disso, os três capítulos do livro, sendo o primeiro dedicado a tratar de "A escolha dos eleitos", o segundo é intitulado como "Jogos sérios e jogos de seriedade" e o terceiro e último "Aprendizes ou aprendizes de feiticeiro?". Por fim, a conclusão do texto.

A operação realizada por Bourdieu e Passeron mostra que o termo "herdeiro" revela muito mais que bens materiais ou o capital econômico gerado por uma família. Traz à tona uma denúncia de uma sucessão do capital cultural 
vinculado a um capital econômico de famílias mais bem favorecidas economicamente, o que facilita o acesso à escola e, depois, à formação acadêmico/ profissional. Aqui, o conceito de capital cultural é acionado pelos autores para mostrar que elementos culturais, como livros, acesso a espetáculos musicais, ao teatro, viagens, às mídias, ao cinema, às exposições de artes etc. constituem uma herança cultural que, depois, na escola, revelam-se como conhecimentos distintos em relação aos saberes escolares, como se estes últimos fossem, para aqueles que provêm de classes mais favorecidas, apenas um saber parcial.

Operando com os três autores clássicos da Sociologia, Bourdieu e Passeron mobilizam Durkheim, Weber e Marx em suas análises. Em relação a Durkheim, o duplo papel e dilema da educação, que ao mesmo tempo que homogeneiza, também diferencia. Marx é visivelmente acionado em relação à oposição entre dominantes e dominados, apesar que os autores utilizam termos distintos, ou seja, classes mais favorecidas e menos favorecidas, mostrando que não é só pelo capital econômico que se define isso, mas também pelas possíveis diferenças naquilo que constituiria uma "classe". Quanto a Weber, este é utilizado quando Bourdieu e Passeron falam em tipo ideal, um "tipo ideal estudantil", inspirado na perspectiva weberiana daquele estudante que herda 278 bens culturais, e com isso, garante privilégios escolares.

Na apresentação do livro, intitulado "Por que ler Os herdeiros meio século depois?", lone Ribeiro Valle contextualiza toda a obra, enfatizando que o grande mérito foi o desmonte do mito "[... d da escola republicana liberadora, proclamada como instrumento (político) de democratização e de promoção da mobilidade social." (p. 9). Segundo Valle, a obra nos mostra a maneira distinta - um habitus distinto? - como a origem social, e, portanto, os fatores culturais, determinam as escolhas em relação ao processo de escolarização, em que às classes dominantes os saberes escolares são transmitidos "como por osmose" e aos filhos das classes desfavorecidas "a cultura escolar é aculturação", ou seja, uma aprendizagem desvinculada de seu contexto social, artificial.

$\mathrm{Na}$ "Advertência", os autores justificam o porquê de tal escolha dos dados tratados na obra, ou seja, o motivo pelo qual isolam para suas análises os dados dos estudantes de letras: é porque são, nesses estudantes, que é possível se identificar com maior clareza a influência da origem social e os fatores culturais da desigualdade quanto à escola, por meio da eliminação, relegação e atraso. Eles desvelam que a origem social e o pertencimento a determinada 
classe social implica determinada maneira de lidar com a escolarização, perpetuando formas de determinismos sociais via escola.

Operando dessa maneira, de estranhar o que naturalizamos, neste caso, o papel da escola, questionando mecanismos de homogeneização, de universalidade e de igualdade de condições, é que os autores, no primeiro capítulo, "A escola dos eleitos", explicitam seu pressuposto, pelas análises estatísticas realizadas e apresentadas na obra: há uma "[...] distribuição desigual das chances escolares segundo a origem social, rapazes e moças estão grosso modo em condições iguais" (p. 17). Em síntese, poderíamos pensar duas "leis gerais" naquele contexto dos alunos franceses: a probabilidade de acesso a um determinado curso superior segundo a origem social é maior para aqueles que são originários de classes sociais mais favorecidas; e, em geral, aos homens há uma destinação aos cursos de ciências; às mulheres, aos cursos de letras.

Considerando que não são apenas as questões econômicas que determinam as condições de escolarização e de prosseguimento na carreira profissional, os autores citam também os obstáculos culturais, momento em que o papel da escola e de sua ação homogeneizante é focado, sendo um lócus de uma determinada cultura dominante que determina às classes desfavorecidas quais saberes devem ser mencionados e aprendidos, inclusive àqueles que não pertencem a essa classe, sofrendo um processo forçado de aculturação (adaptabilidade).

Apesar de parecer haver um determinismo nas análises em relação ao capital cultural se reproduzir por conta própria, em dois momentos, no primeiro capítulo, eles tratam de explicar que a origem social elevada não favorece automaticamente uma igualdade de benefícios.

Num único momento, é possível se pensar numa "luz no fim do túnel", um aspecto de otimismo, em suas análises sobre o que é herdado culturalmente. Naquilo que pode ser mais esmagador possível, em relação ao destino social pela sua origem de classe, Bourdieu e Passeron (2014, p. 43) sustentam que aos desfavorecidos, é possível que eles: "[...] também podem, excepcionalmente, encontrar no excesso de sua desvantagem a provocação para superá-la $[\ldots]^{\prime \prime}$, escapando à sorte comum.

No segundo capítulo, "Jogos sérios e jogos de seriedade", os autores tratam desse mecanismo de aculturação realizado pela escola e pelas 
universidades como um "jogo" - o jogo intelectual, o jogo ideológico, jogo das transfigurações simbólicas. Considerando o pressuposto principal da obra, isto é, que a origem social determina a forma ou o sucesso escolar/profissional, a partir da ideia do esforço e da própria meritocracia, neste capítulo, Bourdieu e Passeron desconstroem também a ideia comum de que os estudantes constituem um grupo social homogêneo.

Assim, apesar de o jogo parecer ser o mesmo para aqueles que o encaram e se dispõem a disputá-lo, as condições anteriores já são uma diferenciação na forma de atuação no jogo, apesar de as regras serem as mesmas. Isso significa dizer que o "capital de informações", ou o capital cultural herdado e presente na vida daqueles oriundos das classes mais favorecidas permite que determinados estudantes tenham, na escola/na universidade, apenas mais uma forma de conhecimento, não aquela que define seu destino social em relação à cultura e à formação profissional.

No terceiro e último capítulo, cujo título é "Aprendizes ou aprendizes de feiticeiro?", os autores constroem, para fins heurísticos, o tipo ideal da conduta estudantil, pensando nos fins da educação e dos seus meios. Como algo presente em toda a obra, explicita-se, por exemplo, o habitus familiar, mos280 trando que a profissão dos pais determina uma forma de entendimento sobre sua futura profissão.

A tensão provocativa do título deste último capítulo se apresenta em relação a delegar à magia a única forma daqueles, oriundos de famílias de classes sociais menos favorecidas, superarem, ou, ao menos, se igualarem, aos dons intrínsecos daqueles estudantes de origem familiar mais favorecida. Isso apareceria, por exemplo, nos momentos de avaliação dos processos educativos: os procedimentos racionais para observar como o processo de aculturação foi realizado se colocam como "[...] ritos de prognosticação por meio dos quais se faz esforço para prever o sujeito ou a nota" (p. 87).

Ao concluírem a obra, Bourdieu e Passeron retomam a crítica da cegueira às desigualdades sociais das pesquisas sociológicas da época, que estavam condicionadas a tratar essas desigualdades aparentes como "naturais", como uma desigualdade de dons. Assim, tais autores, ao elegerem a educação escolar como objeto sociológico, acabaram fundando uma sociologia das desigualdades culturais, mostrando, no livro Os herdeiros, que a classe estudantil é uma classe heterogênea, que age das maneiras mais distintas no campo educacional, sendo que a força motriz das ações em muito se dá pelo 
pertencimento a uma classe mais ou menos favorecida, e disso fazendo parte todo o capital cultural herdado.

Ler Os herdeiros faz tomar contato com uma obra que é um clássico da Sociologia, em especial da Sociologia da Educação, não pela sua transposição ao atual contexto brasileiro lque pode indicar diferenças, tanto históricas, como da própria constituição societária daquil mas pela maneira como aspectos naturalizados da educação/formação profissional são acionados empiricamente e relacionados ao arcabouço teórico-conceitual de Pierre Bourdieu.

Ms. Cristiano Mezzaroba Universidade Federal de Sergipe | UFS Departamento de Educação Física Doutorando do Programa de Pós-Graduação em Educação/UFSC E-mail | cristiano_mezzaroba@yahoo.com.br

Recebido 11 jan. 2015 Aceito 20 fev. 2015 